\title{
EL TRABAJO DEL HOGAR Y SU REGULACIÓN EN AMÉRICA LATINA. UN ESTUDIO COMPARADO*
}

\author{
DOMESTIC WORK AND ITS REGULATION \\ IN LATIN AMERICA. A COMPARATIVE STUDY \\ LE TRAVAIL DOMESTIQUE ET SA REGULATION \\ EN AMERIQUE LATINE. UNE ÉTUDE COMPARATIVE
}

\section{Diana PÉREZ PADRÓN*}

\begin{abstract}
RESUMEN: El trabajo doméstico o del hogar se ha considerado como una actividad que no reporta un valor a la economía de los países. El ambiente de discriminación en el que se ven inmersas las personas que desempeñan esta actividad ha traído como consecuencia una situación de vulnerabilidad que afecta principalmente a mujeres, aunado a la problemática que enfrenta este sector laboral en diversos países, pues no se cuenta con el marco jurídico ni con políticas públicas integrales que propicien, en términos utilizados por la OIT, el trabajo digno o decente.

Este estudio tiene como finalidad brindar información para dar a conocer la situación jurídica tan compleja en la que se desarrolla este grupo de trabajadores a partir de un análisis que tendrá como base el método comparativo de diversas legislaciones nacionales que regulan el trabajo doméstico o del hogar en América Latina. Derivado de esta tarea, se busca exponer el trabajo y los esfuerzos de cada país, en el ámbito legislativo, tendientes a eliminar las barreras que impiden la formalización de las relaciones de trabajo, el ejercicio de derechos humanos y laborales, partiendo de la premisa de que todo trabajador, independientemente de la actividad que realice, debe disfrutar de un ambiente sin discriminación, con acceso a las prestaciones laborales y de seguridad social.
\end{abstract}

* Recibido el 2 de octubre de 2019 y aceptado para su publicación el 25 de marzo de 2020.

** Maestra en Ciencias Jurídicas por la Universidad Autónoma de Baja California; licenciada en Derecho por la Universidad Autónoma de Baja California, obteniendo mención honorífica, y docente de asignatura, impartiendo las materias de Medios alternos de solución a controversias, Introducción al estudio del derecho y Seminario de tesis. 
Palabras clave: trabajo del hogar, derechos laborales, derecho comparado, reconocimiento, trabajo decente.

ABSTRACT: Domestic or household work has been considered as an activity that does not report a value to the economy of the countries. The environment of discrimination in which people who carry out this activity are immersed has resulted in a situation of vulnerability that mainly affects women, coupled with the problems faced by this labor sector in various countries as there is no legal framework nor with comprehensive public policies that propitiate, in terms used by the ILO, decent or decent work.

This study aims to provide information to publicize the complex legal situation in which this group of workers develops, this, based on an analysis that will be based on a comparative method of various national laws that regulate domestic work or Home in Latin America. Derived from this task, it seeks to expose the work and efforts of each country in the legislative field aimed at eliminating the barriers that prevent the formalization of labor relations, the exercise of human and labor rights, based on the premise that everything worker, regardless of the activity you do, must enjoy an environment without discrimination, with access to work and social security benefits.

Keywords: domestic work, labor rights, comparative law, recognition, decent work

RÉSUMÉ: Le travail domestique ou domestique a été considéré comme une activité qui ne rapporte pas de valeur à l'économie des pays. L'environnement de discrimination dans lequel les personnes qui exercent cette activité sont immergées a créé une situation de vulnérabilité qui touche principalement les femmes, ainsi que les problèmes auxquels ce secteur du travail est confronté dans plusieurs pays en raison de l'absence de cadre juridique. ni avec des politiques publiques globales qui favorisent, en termes utilisés par l'OIT, le travail décent ou décent.

Cette étude a pour objectif de fournir des informations permettant de faire connaitre la situation juridique complexe dans laquelle évolue ce groupe de travailleurs, et ce, sur la base d'une analyse qui reposera sur une méthode comparative des différentes législations nationales régissant le travail domestique ou le travail domestique. Maison en Amérique latine. Dérivé de cette tâche, il cherche à exposer le travail et les efforts de chaque pays dans le domaine législatif en vue d'éliminer les obsta- 
cles qui empêchent la formalisation des relations de travail, l'exercice des droits de l'homme et du travail, en partant du principe que le travailleur, quelle que soit l'activité que vous exercez, doit bénéficier d'un environnement sans discrimination, avec accès au travail et aux prestations de sécurité sociale.

Mots clés: travail domestique, droits du travail, droit comparé, reconnaissance, travail décent.

Sumario: I. Preámbulo. II. La transición del trabajo doméstico al trabajo del hogar. Aproximaciones terminológicas. III. Justificación del estudio entre los países de Argentina, Ecuador, Chile, México y Uruguay. IV. Análisis de la legislación en Latinoamérica. V. Marco jurídico internacional. VI. Conclusiones. VII. Fuentes de consulta.

\section{PREÁMBULO}

$\square$ xisten numerosas concepciones y trato que recibe el trabajo doméstico en las diversas regiones del mundo. En varios países de América Latina las condiciones bajo las que se desarrolla el trabajo doméstico encuentran sus propios matices y aspectos característicos en cada región, tomados a consideración para formular sus sistemas normativos. No obstante, pertenecen a culturas similares, con un sistema jurídico común. Por esta razón es que disciplinas como el derecho se dan a la tarea de examinar los sistemas jurídicos, a fin de entender esta diversidad y, en algunos casos, encontrar solución a problemáticas de índole nacional inspiradas en las tendencias jurídicas del mundo.

Por ello se realizará el presente estudio comparado entre las legislaciones de los países de Argentina, Chile, Ecuador, Uruguay y México, a fin de poder presentar un panorama sobre la situación jurídica en la que se encuentran los trabajadores domésticos en dicho territorio, lo anterior a partir de una serie de indicadores que se tomarán como base para compararlos. En este sentido, los principales indicadores serán cómo define cada uno de los países al trabajo doméstico; cómo se regula esta actividad y cuáles son las obligaciones de las partes que forman la relación de trabajo; las características que presenta el régimen de los trabajadores domésticos establecido en la ley y las condiciones de trabajo, destacando el pago de salario, la jornada, 
los periodos de descanso y el acceso a la seguridad social, entre otras prestaciones.

El análisis y descripción de los anteriores indicadores permitirá, por un lado, que la perspectiva de derechos al trabajo doméstico se amplíe al momento de contrastar los casos, y por el otro, identificar el grado de igualdad o discrepancia que se presentan en las leyes que contemplan el trabajo doméstico en los países de referencia, a efecto de establecer en qué medida se reconocen y respetan los derechos fundamentales de los trabajadores domésticos, los cuales se encuentran plasmados en diversos instrumentos jurídicos internacionales.

Asimismo, para la realización del presente estudio se hará alusión a un marco jurídico internacional de referencia que regule este tipo de relación de trabajo, destacando parámetros que ofrece la Organización Internacional del Trabajo (OIT) a partir de los convenios adoptados por la misma, así como la situación que guardan estos convenios en relación con cada país objeto de análisis.

\section{LA TRANSICIÓN DEL TRABAJO DOMÉSTICO \\ AL TRABAJO DEL HOGAR. APROXIMACIONES TERMINOLÓGICAS}

La definición de trabajo doméstico, e incluso de trabajador doméstico, ha sido una labor compleja en virtud del contexto social y cultural que se vive en cada país. Como ejemplo basta señalar que las labores que comprende esta actividad son muy variadas, pues van desde la limpieza del hogar hasta el cuidado de personas mayores o de enfermos.

En este sentido, el contexto de cada país influye en la denominación que recibe esta actividad y a la persona que realiza este trabajo. Paulatinamente, algunos países en sus procesos de reforma han abandonado el uso del adjetivo doméstico, pues denota un carácter peyorativo atendiendo a su significado (perteneciente o relativo a la casa u hogar, dicho de un criado, que sirve en una casa ${ }^{1}$ ), mientras que otros optan por conservar este término.

Algunas legislaciones que regulan a este colectivo de trabajadores utilizan los términos trabajadores del hogar (Bolivia, México, Perú), trabajo doméstico (Bra-

1 Real Academia Española, "Doméstico", disponible en: https://dle.rae.es/srv/search?m $=30 \ll w=d o m \% C 3 \%$ A9stico (fecha de consulta: 18 de junio de 2019). 
sil, Costa Rica, Paraguay, Uruguay), o personal de casas particulares (Argentina), por mencionar algunos.

La necesidad de establecer una definición de carácter universal ha sido una de las inquietudes de la OIT, por lo que, en el Convenio sobre las trabajadoras y los trabajadores domésticos, número 189 (en adelante Convenio 189), se proponen las siguientes definiciones y una excepción:

- La expresión trabajo doméstico designa el trabajo realizado en un hogar u hogares o para los mismos.

- La expresión trabajador doméstico designa a toda persona, de género femenino o género masculino, que realiza un trabajo doméstico en el marco de una relación de trabajo.

- Una persona que realice trabajo doméstico únicamente de forma ocasional o esporádica, sin que este trabajo sea una ocupación profesional, no se considera trabajador doméstico. ${ }^{2}$

Estas definiciones, si bien nos proporcionar una referencia, no delimitan la diversidad de tareas que puede incluirse en esta actividad, por lo que la labor de precisar una definición de esta actividad no termina con establecer un vocablo para su identificación, sino también en delimitar las actividades que comprende el trabajo del hogar y sus características. Al respecto, del propio contenido del Convenio 189 se pueden desprender las siguientes particularidades:

- La prestación del servicio personal subordinado se desarrolla en el hogar de una familia.

- Puede comprender actividades como limpieza, preparación de alimentos, lavar y planchar, mantenimiento del hogar.

- Puede incluir tareas más especializadas como jardinería, manejo de vehículos, vigilancia, cuidado y atención a niños, adultos mayores y enfermos.

- El personal se encuentra bajo la dirección y también la supervisión del jefe del hogar, quien no obtiene beneficio económico del trabajo realizado.

2 Convenio sobre las trabajadoras y los trabajadores domésticos, número 189, OIT, disponible en: https://mwn.ilo.org/dyn/normlex/es/f?p=NORMLEXPUB:12100:0::NO::P12100_INS TRUMENT_ID:2551460 (fecha de consulta: 18 de junio de 2019). 
Debido a tales características, las personas trabajadoras del hogar se han considerado como un grupo de difícil protección, toda vez que se trata de una actividad históricamente infravalorada respecto de las condiciones de trabajo contempladas en marcos jurídicos precarios. Como bien se precisó, se realiza en un hogar particular — de ahí que se considere como una actividad improductiva-, frecuentemente para más de un patrón, el salario que perciben puede ser en especie, los ingresos son inestables ante la ausencia de un salario mínimo, en la mayoría de los casos el horario de trabajo queda sujeto a las necesidades de los miembros de la familia del hogar y no en razón de un periodo de horas establecido.

Otro de los puntos a destacar es que el trabajo doméstico es considerado una labor que no requiere de una preparación técnica por medio de un sistema de aprendizaje, como sucede con otras profesiones, de ahí que también tienda a ser descalificado.

Ante este escenario, es importante analizar cómo es que cada país ha realizado esfuerzos para superar los obstáculos a los que se enfrenta el trabajo del hogar, y que van desde la implementación de políticas públicas hasta modificaciones en sus leyes y códigos del trabajo, así como la adopción de instrumentos internacionales, con el fin de ampliar la protección para este sector laboral.

\section{JUSTIFICACIÓN DEL ESTUDIO ENTRE LOS PAÍSES de Argentina, ECuAdor, Chile, MÉxico y Uruguay}

Para el desarrollo del presente estudio se tomarán, como base en la comparativa, las legislaciones laborales de los países de Argentina, Ecuador, Chile, Uruguay y, por supuesto, México, países con una cultura, lengua y religión similares, además de pertenecer a la familia del derecho romano germánico y a la red de países que conforman América Latina, región en la que, según datos de la OIT, se concentra el 27\% del trabajo doméstico mundial. Se estima que, aproximadamente, 18 millones de latinoamericanos trabajan en labores del hogar, representando al 7\% de todos los ocupados en la región. ${ }^{3}$

3 "Panorama temático laboral. Presente y futuro de la protección social en América Latina y el Caribe", Suiza, OIT, 2018, p. 26, disponible en: https:// www.ilo.org/wcmsp5/groups/ public/---americas/---ro-lima/documents/publication/woms_633654.pdf (fecha de consulta: 20 de junio de 2019). 
Los criterios que sirven de justificación para la elección de estos países radican en lo siguiente: índices de protección social, ratificación del Convenio 189 de la OIT y legislación especial sobre trabajo del hogar.

En relación con el primer criterio, es importante hacer alusión a un estudio realizado por la OIT, el denominado "Panorama Social de América Latina y el Caribe 2015", el cual toma como referencia diversos países en los que la protección al trabajo del hogar varía en ciertas proporciones, destacándose Argentina, Ecuador, Chile y Uruguay, siendo estos dos últimos los que presentan mayores porcentajes de cobertura en cuanto a los sistemas de seguridad social (42.3\% y $43.2 \%$, respectivamente), y que sirven como primer punto para tomar como referencia en el presente análisis y compararlos con México, que hasta hace poco mantenía una incorporación voluntaria al Instituto Mexicano del Seguro Social (IMSS), tema del que se hablará posteriormente.

Los porcentajes relativos a la cobertura de seguridad social podemos observarlos en la siguiente gráfica:

\section{GRÁFICA 1}

COBERTURA DE LOS SISTEMAS DE SEGURIDAD SOCIAL

\section{AL TRABAJO DOMÉSTICO}

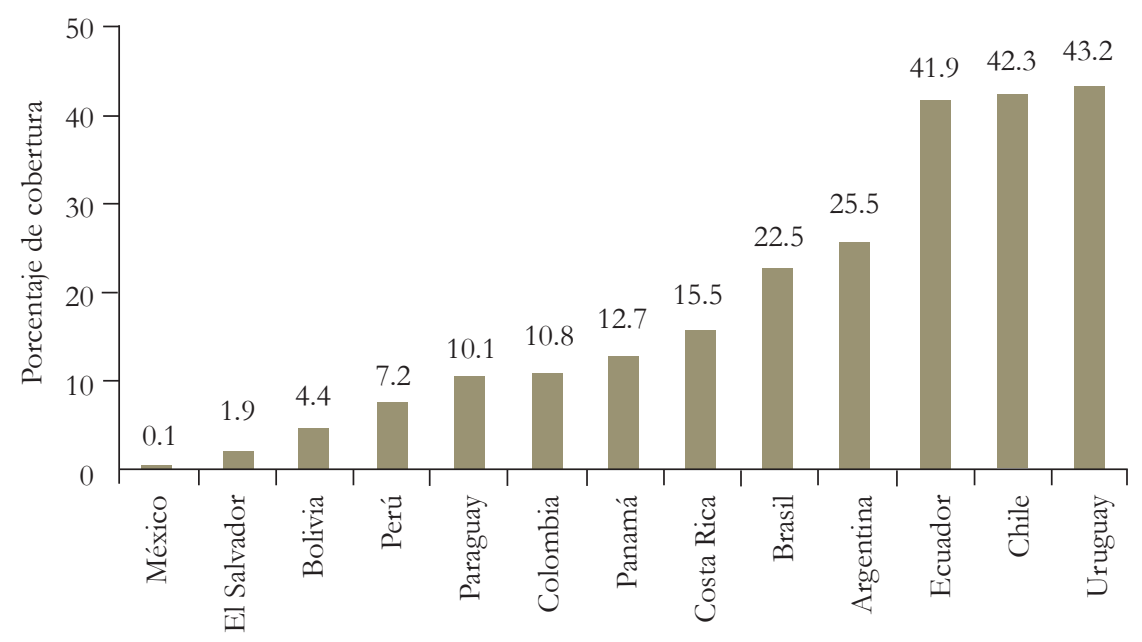

FUENTE: Panorama Laboral de América Latina y el Caribe 2015, OIT. 
En lo relativo a la ratificación del Convenio 189 de la OIT y la Recomendación 201, es importante mencionar el estado que guarda este convenio respecto a cada país objeto de estudio, en virtud de que la ratificación de este instrumento internacional permite ampliar la protección del trabajo del hogar en múltiples aspectos relacionados con las condiciones en que se desarrolla. Recordemos que este convenio fue adoptado por la OIT el 11 de junio de 2011 en su Conferencia, y hasta la fecha son 24 países los que lo han ratificado. Respecto a América Latina, la ratificación en los países que se analizarán tuvo lugar en las siguientes fechas:

\author{
TABLA 1 \\ RATIFICACIONES DEL CONVENIO 189 DE LA OIT \\ EN PAÍSES SELECCIONADOS
}

\begin{tabular}{|c|c|}
\hline Argentina & 24 de marzo de 2014 \\
\hline Chile & 10 de junio de 2015 \\
\hline Ecuador & 18 de diciembre de 2013 \\
\hline México & Sin ratificar \\
\hline Uruguay & 14 de junio de 2012 \\
\hline
\end{tabular}

FUENTE: Elaboración propia con datos de la OIT. ${ }^{4}$

Como es de observarse, de los países seleccionados, México no ha ratificado el citado convenio. No obstante, esta situación en particular sirve para contrastarla con la de aquellos países que sí lo ratificaron, pues, para efectos de la comparativa, no sólo se consideran las características comunes que comparten los países, sino también sus diferencias, a fin de enriquecer este estudio comparado.

Otro de los factores a considerar para el estudio comparado es el estado que guarda la regulación del trabajo del hogar en cada uno de los países, por lo que, de manera particular, se analizarán leyes generales sobre el trabajo a fin de detectar disposiciones que se relacionen con esta actividad, así como leyes especiales encargadas específicamente de regularla, como es el caso de la Ley 26.844 Régimen Especial de Contrato de Trabajo para el Personal de Casas

4 Ratificación del Convenio 189, disponible en: https:// wmm.ilo.org/dyn/normlex $/$ es $/ f ? p=N$ ORMLEXPUB:11300:0::NO::P11300_INSTRUMENT_ID:2551460 (fecha de consulta: 20 de junio de 2019). 
Particulares (Argentina), Ley 18.065/2006 De Trabajo Doméstico (Uruguay), y, en el caso de México, el reformado capítulo XIII de la Ley Federal del Trabajo, denominado "Personas trabajadoras del hogar".

\title{
Datos generales
}

Sobre el porcentaje de asalariados que se dedican al trabajo doméstico, para el año 2015 la OIT estimó cierto número de casos con base al total de asalariados en cada país de Latinoamérica, observándose que hubo un incremento en países como Costa Rica, México y República Dominicana, ${ }^{5}$ como se puede apreciar en la siguiente gráfica:

\author{
GRÁFICA 2 \\ Porcentaje DE ASALARIADOS \\ EN EL TRABAJO DOMÉSTICO \\ EN PAÍSES DE LATINOAMÉRICA, 2005-2015
}

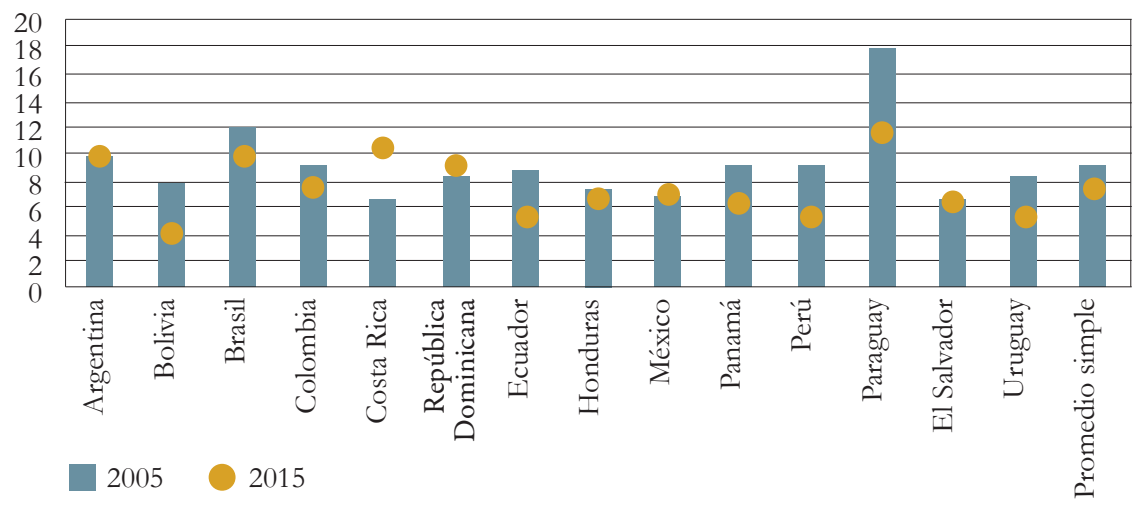

FUENTE: Panorama Laboral de América Latina y el Caribe 2017, OIT.

Otras cifras revelan la distribución de los asalariados bajo el régimen del trabajo doméstico por sexo en cada región del mundo, en el entendido de que es desarrollado, en su mayoría, por mujeres, como se muestra a continuación:

5 “Panorama Laboral de América Latina y el Caribe 2017”, Suiza, OIT, 2017, p. 81, disponible en: https:// www.ilo.org/womsp5/groups/public/---americas/---ro-lima/documents/publication/ woms_613957.pdf (fecha de consulta: 22 de junio de 2019). 


\section{GRÁFICA 3}

\section{DISTRIBUCIÓN DEL TRABAJO DOMÉSTICO SEGÚN SEXO Y REGIÓN}

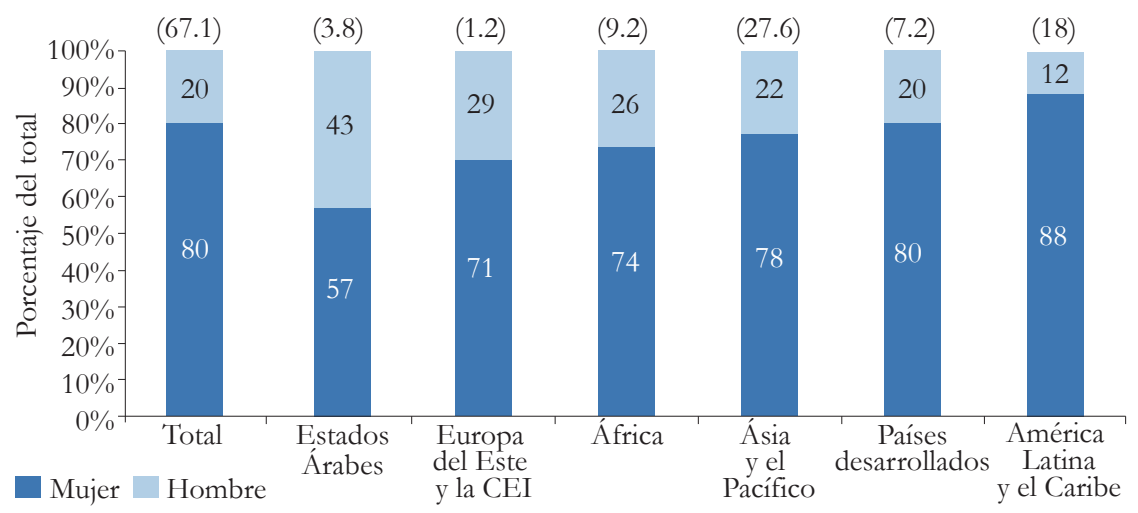

FUENTE: Protección social del trabajo doméstico: tendencias y estadísticas, OIT, $2016 .{ }^{6}$

Como puede observarse, la distribución por región presenta diferencias notorias. Asia-Pacífico y América Latina-Caribe concentran, en conjunto, la mayoría de las personas trabajadoras remuneradas del hogar en el mundo. La característica que persiste en cada región es la fuerte participación de la mujer en esta actividad; es decir, es un trabajo realizado principalmente por mujeres y que en América Latina se ve reflejado en un $88 \%$ de mujeres contra un 12\% de hombres (diferencia del 76\%). Puede verse que, en el caso de los Estados Árabes, entre la mano de obra masculina y femenina dedicada a esta labor no existe demasiada diferencia (apenas un 14\%), lo que rompe con el paradigma de que esta actividad es exclusiva del sector femenino en países donde aún subsiste una cultura de represión contra la mujer.

\section{ANÁLISIS DE LA LEGISLACIÓN EN LATINOAMÉRICA}

En América Latina se han producido diversas modificaciones a las legislaciones de los países que la integran; estas variaciones van desde financieras y educativas hasta de derechos humanos y, por supuesto, en materia de traba-

6 "Protección social del trabajo doméstico: tendencias y estadísticas", OIT, 2016, p. 6, disponible en: https://wmw.ilo.org/womsp5/groups/public/---ed_protect/---soc_sec/documents/publica tion/woms_458939.pdf(fecha de consulta: 22 de junio de 2019). 
jo. Los países de Argentina, Chile, Ecuador, México y Uruguay servirán de base para la siguiente comparativa en el aspecto normativo, en virtud de las particularidades que presenta cada una de las normas que regulan el régimen general de trabajo y, de forma específica, el trabajo doméstico o del hogar.

\section{Marco jurídico nacional de referencia}

- Argentina. Podemos mencionar la Constitución Política de Argentina, en su artículo 14 bis, y la Ley 26.844 Régimen Especial de Contrato de Trabajo para el Personal de Casas Particulares.

- Chile. Los fundamentos los encontramos en la Constitución Política de la República de Chile, en su artículo 19, numerales 16, 17, 18 y 19; en el Código del Trabajo, en el capítulo V, denominado "Del contrato de trabajadores de casa particular", artículos 146-152 bis, así como la Ley 20.255 (sobre el sistema de pensiones), Ley 20.279 (sobre el ingreso mínimo), artículo 2o., Ley 20.336 (sobre el descanso de los trabajadores de casa particular), artículo único, y la Ley 20.786 (sobre la jornada, descanso y composición de la remuneración de los trabajadores de casa particular, y prohíbe la exigencia de uniforme en lugares públicos), artículo único.

- Ecuador. Específicamente en la Constitución de la República de Ecuador, en los artículos 34, 35, 325, 326, 327, 328, 330, 331, 332, 333, y en el Código de Trabajo, el capítulo I, titulado "Del servicio doméstico", que comprende los artículos 262-270.

- México. El marco jurídico laboral que regula el trabajo de manera general y el doméstico se encuentra principalmente en tres ordenamientos, la Constitución Política de los Estados Unidos Mexicanos, artículo 123, apartado A; la Ley Federal del Trabajo, capítulo XIII, "Personas trabajadoras del hogar", artículos 331-343, y la Ley del Seguro Social, artículo 12, fracción IV.

- Uruguay. La Constitución Política de Uruguay, en los artículos 53, 54 y 55, y la Ley 18.065/2006 De trabajo doméstico.

\section{Sobre la concepción del trabajo doméstico o del hogar}

En párrafos anteriores se señaló la problemática que se presenta para tratar de definir al trabajo doméstico, lo que radica en la pluralidad de contextos que 
envuelven esta actividad, por lo que cada legislación propone su forma particular de definirlo, las actividades que comprende y señalar excepciones. Para efectos prácticos, se desarrolla el contenido de las legislaciones en estudio en la siguiente tabla:

TABLA 2

DEFINICIONES PARTICULARES

\begin{tabular}{|c|c|c|}
\hline País & Definición & Quedan excluidos \\
\hline $\begin{array}{c}\text { Argentina } \\
\text { Personal } \\
\text { de casas } \\
\text { particulares }\end{array}$ & $\begin{array}{l}\text { Prestación de servicios o eje- } \\
\text { cución de tareas de limpieza, de } \\
\text { mantenimiento, otras activida- } \\
\text { des típicas del hogar, asistencia } \\
\text { personal y acompañamiento a } \\
\text { los miembros de la familia o que } \\
\text { convivan en el domicilio del em- } \\
\text { pleado, y el cuidado no terapéu- } \\
\text { tico de personas enfermas o con } \\
\text { discapacidad. }\end{array}$ & $\begin{array}{l}\text { Las personas jurídicas, personas } \\
\text { emparentadas con el dueño, los } \\
\text { que presten servicio exclusivo de } \\
\text { cuidado y asistencia a enfermos, } \\
\text { los contratados para conducir } \\
\text { vehículos particulares, los que } \\
\text { convivan con el personal de casas } \\
\text { particulares sin que presten este } \\
\text { servicio, los que, además de rea- } \\
\text { lizar tareas domésticas, efectúen } \\
\text { otro tipo de actividad y aquellos } \\
\text { empleados por consorcios. }\end{array}$ \\
\hline $\begin{array}{c}\text { Chile } \\
\text { Trabajadores } \\
\text { de casa } \\
\text { particular }\end{array}$ & $\begin{array}{l}\text { Las personas que se dediquen en } \\
\text { forma continua, a jornada com- } \\
\text { pleta o parcial, al servicio de una } \\
\text { o más personas o de una familia, } \\
\text { en trabajos de aseo y asistencia } \\
\text { propios o inherentes al hogar ... } \\
\text { las personas que realizan labores } \\
\text { iguales o similares en institucio- } \\
\text { nes de beneficencia... }\end{array}$ & No señala de manera expresa. \\
\hline $\begin{array}{l}\text { Ecuador } \\
\text { Servicio } \\
\text { doméstico }\end{array}$ & $\begin{array}{l}\text { Es el que se presta, mediante re- } \\
\text { muneración, a una persona que } \\
\text { no persigue fin de lucro y sólo se } \\
\text { propone aprovechar, en su mo- } \\
\text { rada, de los servicios continuos } \\
\text { del trabajador, para sí solo o su } \\
\text { familia, sea que el doméstico se } \\
\text { albergue en casa del empleador o } \\
\text { fuera de ella. }\end{array}$ & $\begin{array}{l}\text { Los que prestan servicios en hote- } \\
\text { les, bares, fondas, posadas, hospi- } \\
\text { tales o establecimientos análogos. }\end{array}$ \\
\hline
\end{tabular}




\begin{tabular}{|c|c|c|}
\hline País & Definición & Quedan excluidos \\
\hline $\begin{array}{c}\text { México } \\
\text { Personas } \\
\text { trabajadoras } \\
\text { del hogar }\end{array}$ & $\begin{array}{l}\text { Son aquellas que de manera re- } \\
\text { munerada realicen actividades de } \\
\text { cuidados, aseo, asistencia o cual- } \\
\text { quier otra actividad inherente al } \\
\text { hogar en el marco de una rela- } \\
\text { ción laboral que no importe para } \\
\text { la persona empleadora beneficio } \\
\text { económico directo. }\end{array}$ & $\begin{array}{l}\text { Quien realice trabajo del hogar } \\
\text { de forma ocasional o esporádica, } \\
\text { quien preste servicios de aseo, } \\
\text { asistencia, atención de clientes y } \\
\text { otros semejantes, en hoteles, casas } \\
\text { de asistencia, restaurantes, fondas, } \\
\text { bares, hospitales, sanatorios, cole- } \\
\text { gios, internados y análogos. }\end{array}$ \\
\hline $\begin{array}{l}\text { Uruguay } \\
\text { Trabajo } \\
\text { doméstico }\end{array}$ & $\begin{array}{l}\text { Es el que presta, en relación de } \\
\text { dependencia, una persona a otra } \\
\text { u otras, o a una o más familias, } \\
\text { con el objeto de consagrarles su } \\
\text { cuidado y su trabajo en el hogar, } \\
\text { en tareas vinculadas a éste, sin } \\
\text { que dichas tareas puedan repre- } \\
\text { sentar para el empleador una ga- } \\
\text { nancia económica directa. }\end{array}$ & No señala de manera expresa. \\
\hline
\end{tabular}

FUENTE: Elaboración propia con datos de la Ley Federal del Trabajo, México; Ley 26.844, Argentina; Código del Trabajo de Ecuador; Código de Trabajo de Chile, y Ley 18.065/2006, Uruguay.

De manera general, se observa que la actividad comprende un servicio que no importe al patrón algún beneficio económico, además de que se realice en la casa u hogar de una familia. En el caso de Chile, se hace una extensión particular de la aplicación de su legislación a las personas que realicen dichas actividades para una institución de beneficencia.

Sobre las modalidades de la prestación del servicio, la Ley 26.844, de Argentina, distingue dos, las cuales denomina como trabajadores "sin retiro", los que laboran para un mismo patrón y que habitan en el mismo domicilio donde se presta el servicio, y "con retiro", que presenta dos vertientes: aquellos que prestan servicios para un único patrón o para diversos empleadores. Esta terminología es también utilizada por Uruguay, en la Ley 18.06/2006, de manera específica en el artículo 30.

Por su parte, la Ley Federal del Trabajo, en México, a partir de su más reciente reforma del 2 de julio de 2019, refiere las modalidades en el artículo 331 , siendo éstas cuando trabajen para una persona empleadora y habiten en el domicilio donde realizan sus actividades; que trabajen para una persona 
empleadora y que no residan en el domicilio donde se ejecutan las actividades, y que trabajen para diferentes personas empleadoras y que no residan en el domicilio de ninguna de ellas (coloquialmente denominadas de entrada por salida o de planta).

En relación con Chile, el Código de Trabajo no prevé de manera expresa las modalidades, no obstante, del texto se infiere que reconoce las de entrada por salida y de planta. En Ecuador sucede algo similar, pues el artículo 262 del Código de Trabajo, relativo a las modalidades del servicio doméstico, prevé que el trabajador se hospede en la casa del patrón o fuera de ella.

\section{Sobre las formalidades del contrato de trabajo}

Con relación al contrato de trabajo y las formalidades que debe revestir el mismo, se aprecia que en cada uno de los países, en menor o mayor medida, se exigen determinados requisitos para su implementación. En cuanto al deber de celebrar un contrato, a continuación se presenta la siguiente tabla de especificaciones:

TABLA 3

CONTRATO DE TRABAJO

\begin{tabular}{|c|l|l|l|}
\hline País & \multicolumn{1}{|c|}{ Requisitos } & \multicolumn{1}{|c|}{ Registro } & \multicolumn{1}{c|}{ Otras especificaciones } \\
\hline \multirow{5}{*}{ Argentina } & $\begin{array}{l}\text { Requisitos del contrato de } \\
\text { trabajo en general. }\end{array}$ & $\begin{array}{l}\text { Libreta de trabajo } \\
\text { con datos de los pa- } \\
\text { tración de Ingresos certificados, } \\
\text { Público. } \\
\text { remuneraciones, se- } \\
\text { guridad social (equi- } \\
\text { vale a un expediente } \\
\text { laboral). }\end{array}$ \\
\hline \multirow{5}{*}{ Chile } & $\begin{array}{l}\text { Además de los requisitos del } \\
\text { contrato de trabajo en gene- } \\
\text { ral, indicar el tipo de labor a } \\
\text { realizar y el domicilio donde } \\
\text { deberán prestarse los servi- } \\
\text { cios, y en su caso, la obliga- } \\
\text { ción de asistencia a personas } \\
\text { que requieran atención o cui- } \\
\text { dados especiales. }\end{array}$ & $\begin{array}{l}\text { Ante la Inspección } \\
\text { del Trabajo. }\end{array}$ & $\begin{array}{l}\text { Registro del con- } \\
\text { trato dentro de los } \\
15 \text { días siguientes, } \\
\text { entregar copia al } \\
\text { trabajador. }\end{array}$ \\
\hline
\end{tabular}




\begin{tabular}{|c|l|l|l|}
\hline País & \multicolumn{1}{|c|}{ Requisitos } & Registro & Otras especificaciones \\
\hline Ecuador & $\begin{array}{l}\text { Requisitos del contrato de } \\
\text { trabajo en general, en lo que } \\
\text { no se hubiera previsto en el } \\
\text { contrato, se estará a la cos- } \\
\text { tumbre del lugar. }\end{array}$ & $\begin{array}{l}\text { Ante el Misterio del } \\
\text { Trabajo. }\end{array}$ & Sin especificación. \\
\hline México & $\begin{array}{l}\text { Nombre y apellidos del pa- } \\
\text { trón y trabajador; lugar de } \\
\text { trabajo; inicio del contrato } \\
\text { y duración; tipo de traba- } \\
\text { jo a realizar; remuneración, } \\
\text { método de cálculo periodi- } \\
\text { cidad de los pagos; horas de } \\
\text { trabajo; vacaciones anuales } \\
\text { y periodos de descanso; su- } \\
\text { ministro de alimentos y alo- } \\
\text { jamiento, cuando proceda; } \\
\text { casos de terminación de la } \\
\text { relación de trabajo, y herra- } \\
\text { mientas de trabajo que serán } \\
\text { brindadas. }\end{array}$ & $\begin{array}{l}\text { Sin especificación. } \\
\text { Requisitos del contrato de } \\
\text { trabajo en general. }\end{array}$ & $\begin{array}{l}\text { Sin especificación. } \\
\text { condiciones, cuan- } \\
\text { do se trate de per- } \\
\text { distinción de }\end{array}$ \\
\hline sonas migrantes. \\
\hline Sin especificación. \\
\hline
\end{tabular}

FUENTE: Elaboración propia con datos de la Ley Federal del Trabajo, México; Ley 26.844, Argentina; Código del Trabajo de Ecuador; Código de Trabajo de Chile, y Ley 18.065/2006, Uruguay.

Cabe señalar la importancia de que las relaciones de trabajo doméstico o del hogar se concreticen por medio del contrato de trabajo por escrito, ya que en el mismo se estipulan las condiciones de trabajo que regirán durante su vigencia, lo que constituye, además, un elemento de prueba en los juicios laborales que beneficiará a la parte trabajadora.

\section{Sobre los derechos \\ $y$ deberes de las partes}

En las cinco legislaciones analizadas se encuentran aspectos comunes sobre los derechos de las partes, los cuales se resumen, por un lado, en contar 
con periodos de descanso entre jornadas y días de trabajo, alimentos, habitación y, por el otro, los deberes de cuidado y diligencia en las actividades, consideración al empleador y sus familiares.

Sobre los deberes de los trabajadores, de manera específica la Ley 26.844, de Argentina, contempla el deber de guardar el secreto profesional y familiar; en el Código de Trabajo de Chile y Ecuador no se hace referencia, de manera expresa, sobre tales deberes, así como la Ley 18.06/2006, de Uruguay. Por su parte, México, previo a la reforma a su legislación laboral el pasado 2 de julio de 2019, señalaba como deberes para el trabajador guardar al patrón y a su familia consideración y respeto, además del cuidado en la conservación del mobiliario de la casa. El artículo 340 de la Ley Federal del Trabajo, ahora derogado, contemplaba dichos deberes.

En cuanto a las obligaciones del empleador hacia la parte trabajadora, cada legislación establece diversas disposiciones en los siguientes términos:

- Argentina: deber de contratar en favor del personal un seguro por riesgos de trabajo, proveer de ropa y elementos de trabajo, alimentación sana y suficiente (en función de la modalidad de la prestación y jornada contratadas), y para el caso del personal con retiro, que labore para un solo patrón y que entre el término de una jornada y otra se debe conceder un descanso no menor de 12 horas.

- Chile: deber de entregar copia del contrato de trabajo y registrarlo, abstenerse de condicionar la contratación, permanencia o renovación de contrato del personal al uso de uniformes, delantales o análogos en lugares públicos.

- Ecuador: deber de proporcionar alimentación y alojamiento, salvo pacto en contrario, y dentro de sus posibilidades procurar la educación del trabajador. En caso del trabajo de adolescentes con 15 años cumplidos, se obliga a no interferir en el ejercicio del derecho a la educación básica, alimentación, salud, recreación y descanso.

- México: deber de guardar consideración al trabajador, abstenerse de todo mal trato, proporcionar habitación cómoda e higiénica, alimentación sana y garantizar condiciones de trabajo que aseguren la vida y la salud, así como procurar la instrucción del trabajador e inscribirlo ante el IMSS.

- Uruguay: no se establecen obligaciones específicas, salvo lo relativo a la expedición de recibo de salario. 


\section{Sobre la remuneración mínima}

En el caso de Argentina, su legislación señala que el salario de los trabajadores en casas particulares será fijado por la Comisión Nacional de Trabajo en Casas Particulares (CNTCP), la cual establece un salario por tipo, modalidad y categoría profesional, determinado de manera periódica a través de sus resoluciones. Sobre el pago del salario; debe realizarse en días hábiles, en el lugar de trabajo y durante las horas que comprenda éste, además, se debe elaborar recibo, debiendo entregar uno al trabajador.

Actualmente se encuentra en vigor la resolución número 2/2019,7 emitida por la CNTCP, que abarca el periodo de vigencia a partir del 5 de julio de 2019, en tanto se publique una nueva resolución con las actualizaciones de los montos de salarios mínimos y categorías profesionales. Las categorías establecidas por la Comisión comprenden las de supervisora, personal para tareas específicas, caseros, asistencia y cuidado de personas y personas para tareas generales. ${ }^{8}$

Chile, por su parte, señala que la remuneración de los trabajadores de casa particular se fijará de común acuerdo entre las partes y en moneda de curso legal, sin que pueda comprender los alimentos y la habitación, los cuales siempre serán de cargo del empleador (artículo 151 del Código de Trabajo). Mientras que Ecuador, en su Código de Trabajo, establece de forma implícita que las partes pueden fijar la remuneración.

En México los trabajadores del hogar pueden recibir su salario de manera fraccionada; es decir, comprende el pago de una cantidad en efectivo, pudiendo fijarse una parte en especie, que corresponde a alimentos y habitación, según sea el caso, la cual no podrá exceder de un $50 \%$ del que se pague en efectivo, según el artículo 335 de la Ley Federal del Trabajo.

Asimismo, por disposición expresa, existe la obligación de la Comisión Nacional de los Salarios Mínimos (Conasami) de fijar los salarios profesionales para el sector doméstico. Sobre este punto, la Conasami ha sido omisa, en el sentido de fijar tanto el salario o, en su caso, las categorías profesionales que comprende esta actividad. No obstante, recientemente la Comisión manifestó una propuesta de salario diario para esta actividad, que, de acuerdo con sus estudios, estimó prudente la cantidad de $\$ 248.72$ para el trabajo en el hogar, que

7 Unión Personal Auxiliar de Casas Particulares, Resolución de la Comisión Nacional de Trabajo en Casas Particulares en Argentina, disponible en: https:/ / mww.upacp.org.ar/?page_ $i d=1329$ (fecha de consulta: 20 de julio de 2019).

8 Idem. 
de ser aprobado entraría en vigor en el año 2020. Sin duda, se trataba de otra deuda que la justicia social tenía pendiente con este grupo de trabajadores. ${ }^{9}$

Finalmente, la Ley 18.065/2006, de Uruguay, en lo relativo al salario, dispone la incorporación de los trabajadores al sistema de categorías y salarios fijados por el Ministerio de Trabajo y Seguridad Social.

Del análisis anterior es importante atender la situación en la que se encuentran los trabajadores domésticos en México. En definitiva, con el ánimo de garantizarles una remuneración mínima, se debe exhortar a la Conasami a que fije los salarios mínimos que en futuro impactarían al momento de su registro al IMSS para efectos del salario base de cotización, así también, eliminar las formas de pago en especie o, en su caso, reducir el 50\% que permite la Ley Federal del Trabajo para que no sean descontadas del salario. Se destaca la labor de Argentina, que, a través de la CNTCP, es trascendental con el hecho de fijar salarios mínimos por categorías, generando seguridad sobre los mínimos legales y poder acceder a otro tipo de prestaciones, como las de seguridad social, pues el salario está íntimamente vinculado a éstas.

\section{Sobre la jornada de trabajo \\ y periodos de descanso}

Respecto a la jornada en el trabajo doméstico o del hogar, la Ley 26.844, de Argentina, ha establecido el máximo de ocho horas diarias, sin importar la modalidad de la prestación del servicio. En el caso del personal bajo la modalidad con retiro, los descansos consisten en un reposo diario nocturno de nueve horas mínimas consecutivas (en caso de interrupción serán remuneradas) y un descanso diario de tres horas continuas entre las actividades matutinas y vespertinas.

En el caso de Chile, se establecen ciertos parámetros cuando se trata de trabajadores que habitan o no en su lugar de trabajo. En el primero de los casos, no estarán sujetos a horario, sino que será determinado por la naturaleza de la labor, debiendo tener un descanso mínimo de 12 horas diarias. Al término de la jornada diaria y el inicio de la siguiente, el descanso será ininterrumpido, de un mínimo de nueve horas. En el segundo supuesto (cuando no habitan en el lugar de trabajo), la jornada no podrá exceder de

9 Comisión Nacional de los Salarios Mínimos, disponible en: https:/ / www.gob.mx / conasami/ prensa/ hasta-diciembre-se-fijaran-los-salarios-minimos-generales-y-profesionales-donde-se-incluira-el-de-lastrabajadoras-del-hogar (fecha de consulta: 20 de julio de 2019). 
45 horas semanales. Por su parte, el periodo entre el inicio y el término de las labores no podrá exceder de 12 horas continuas.

Ecuador dispone que para el servicio doméstico deben observarse jornadas de trabajo y descanso de cinco días a la semana o 40 horas semanales, y los días sábados y domingos como días de descanso. Si no pudiera interrumpirse el trabajo en tales días, se designará otro tiempo igual de la semana para el descanso, mediante acuerdo entre empleador y trabajadores.

Por otro lado, México, en su Ley Federal del Trabajo, señala que en el caso de las personas que residan en el domicilio donde realizan sus actividades deben disfrutar de un descanso mínimo diario nocturno de nueve horas consecutivas, y de un descanso mínimo diario de tres horas entre las actividades matutinas y vespertinas, sin que la jornada diaria diurna pueda excederse de las ocho horas diarias. Con relación a los periodos en los que no disponen libremente de su tiempo y permanecen a disposición del hogar para responder a posibles requerimientos de su trabajo o que excedan las horas establecidas para cada tipo de jornada, se consideran como horas extras. Asimismo, se prevé el derecho a un descanso semanal de día y medio ininterrumpido, preferiblemente en sábado y domingo, que mediante acuerdo entre las partes se puede acordar la acumulación de los medios días en periodos de dos semanas, días de descanso semanal y días de descanso obligatorio previstos en la ley, y en caso de que estos días se labore, se pagará doble.

Uruguay establece como máxima la jornada laboral de ocho horas diarias y de 44 horas semanales con los siguientes descansos: descanso intermedio de media hora pagada como trabajo efectivo en la modalidad con retiro, mientras que la de "sin retiro" será de dos horas, pudiendo las partes fijar de común acuerdo la hora de inicio y finalización del descanso; descanso semanal de 36 horas ininterrumpidas, que comprenderá el día domingo, pudiendo acordar las partes el día de la semana en que se gozará el descanso restante, y descanso nocturno, que en el caso del régimen "sin retiro" será como mínimo de nueve horas continuas sin poder ser interrumpido.

\section{Sobre las obligaciones en materia de seguridad social a cargo de los patrones}

En el tema de obligaciones en seguridad social para el trabajo en casas particulares, la Ley 26.844, de Argentina, prevé una serie de disposiciones 
particulares en materia de accidentes y enfermedades. Una de las obligaciones principales para el empleador es que toda relación que se suscite entre éste y un trabajador de casa particular invariablemente debe registrarse ante la Administración Federal de Ingresos Públicos (AFIP), y el empleador debe asegurarse de forma obligatoria ante un Asegurador de Riesgos de Trabajo (ART) a fin de contar con un seguro contra este tipo de riesgos.

Seguidamente, se dispone que, en el caso de enfermedad o accidente que impida la prestación del servicio, no afecta el derecho de los trabajadores de recibir su salario hasta por tres meses si su antigüedad es menor de cinco años, o por seis meses si la antigüedad es mayor. Cuando se trate de una enfermedad que la ley refiere como infectocontagiosa, sea del trabajador, del empleador o de alguno de los integrantes del grupo de cualquiera de las partes y que tenga como consecuencia la separación temporal, las medidas contra los riesgos están a cargo del empleador. El deber del trabajador es dar aviso de la enfermedad o accidente, salvo los casos de fuerza mayor, mientras que el empleador debe respetar la remuneración que el trabajador venía percibiendo al acontecimiento del siniestro a efectos del pago de los periodos de tres y seis meses, según sea el caso. Asimismo, se considerarán los incrementos al salario que puedan presentarse a su categoría.

Sobre el caso particular de Chile, el Código de Trabajo señala que, en los casos de enfermedad del trabajador, el patrón debe dar aviso al organismo de seguridad social (Instituto de Previsión Social) y debe conservar su cargo, sin derecho a remuneración, por ocho días. En el supuesto de que tuviera menos de seis meses de servicios; durante 15 días si hubiera laborado más de seis meses y menos de un año, y hasta 30 días si hubiera trabajado más de 12 meses. Además, se prevé que en caso de enfermedad contagiosa (clínicamente calificada) de una de las partes o de las personas que habiten la casa, da el derecho a la otra parte para poner término al contrato.

La legislación de Ecuador no establece de forma específica obligaciones especiales sobre este rubro, salvo el supuesto relativo al trabajador que queda imposibilitado para el trabajo en virtud del servicio prestado al patrón, éste no podrá despedirlo y lo conservará dándole los recursos necesarios para su subsistencia, o lo jubilará. Al reconocerse el derecho a la seguridad social a todo trabajador, disfrutan del régimen general del Instituto Ecuatoriano de Seguridad Social (IESS).

Lo que acontece en México para la persona trabajadora del hogar conforme a las disposiciones de la Ley Federal del Trabajo, en primera instancia, es la obligación del patrón de registrarla ante el IMSS (artículo 337, fracción 
IV), situación que anteriormente no acontecía, pues quedaba a decisión del empleador si afiliar o no ante el Instituto, y en el caso de hacerlo, el régimen de incorporación voluntaria al régimen obligatorio comprendía ciertas limitantes para el disfrute de las prestaciones. Con las reformas en materia de trabajo del hogar (mayo y julio de 2019), los índices de protección a este sector laboral se verán reflejados una vez que se cumpla el plazo que fija el vigésimo quinto transitorio de la Ley Federal del Trabajo (cuando se aprueben y entren en vigor las adecuaciones normativas necesarias), lo que significa que culminadas las fases del Programa Piloto de Incorporación de las Personas Trabajadoras del Hogar al IMSS (un programa de prueba resultado de la resolución al amparo directo en revisión 9/2018 por la Segunda Sala de la Suprema Corte de Justicia de la Nación), la verdadera protección de los trabajadores por medio de una incorporación obligatoria a dicho Instituto aún está en espera. Mientras tanto, la Ley del Seguro Social, en su artículo 12, contempla que este grupo de trabajadores son sujetos de incorporación obligatoria.

En Uruguay se incluye a los trabajadores del servicio doméstico a la cobertura del subsidio por desempleo y en el seguro social del Banco de Previsión Social. Cuando subyace una enfermedad común (no profesional), además del subsidio correspondiente, el trabajador puede optar por la atención de una institución de asistencia médica colectiva o por la que brinda la Administración de los Servicios de Salud del Estado del Ministerio de Salud Pública.

\section{MARCO JURÍDICO INTERNACIONAL}

Los trabajadores domésticos representan un grupo excluido de la protección social, laboral y económica de la que goza cualquier otro grupo de trabajadores; son, principalmente, objeto de discriminación y otras violaciones a derechos humanos.

A fin de propiciar mejores prácticas en los Estados tendientes a la regularización de las relaciones de trabajo doméstico, la OIT adoptó dos instrumentos jurídicos internacionales de suma importancia y trascendencia para esta labor, siendo estos el Convenio 189 y la Recomendación 201, buscando la igualdad entre los trabajadores a partir del reconocimiento de la contribución del trabajo doméstico a la economía mundial. No obstante, sigue siendo una actividad infravalorada en la que las condiciones de trabajo son particularmente discriminatorias y contrarias a los derechos humanos. 
Pese a su adopción en el 2011, son sólo 29 los países ${ }^{10}$ que han ratificado el Convenio 189, mientras que 158 países se han abstenido, y en los cuales figura el Estado mexicano. ${ }^{11}$

El Convenio 189 establece una protección mínima para los trabajadores domésticos, y siendo un ordenamiento que fija las bases para estos mínimos legales de protección, deja a los Estados parte la posibilidad de expandir la cobertura y aplicación. Sin embargo, aunque todas las normas internacionales en materia de trabajo se entienden como aplicables para todos los trabajadores sin excepción, por el carácter "especial” que guarda el trabajo doméstico en la mayoría de las legislaciones, y por su vulnerabilidad, es por lo que se consideró la implementación de normas específicas para la protección de este sector laboral.

Entre sus múltiples disposiciones, el Convenio aporta una definición de trabajo y trabajador doméstico. Por otra parte, del mismo convenio se desprende que el empleador puede ser una persona miembro de la familia que recibe el trabajo o, en su caso, una agencia que emplea trabajadores domésticos y los pone a disposición de los hogares.

La aplicación del Convenio es universal, incluye a los trabajadores domésticos de tiempo parcial, a los que trabajan para varios empleadores, trabajadores nacionales o extranjeros, y con independencia de que residan o no en el lugar de trabajo. En su artículo 3o. se exige a los Estados miembros la adopción de medidas que garanticen la promoción y protección efectivas de los derechos humanos de los trabajadores domésticos, así como de otros derechos y principios en el trabajo relativos a la libertad sindical, la negociación colectiva, la eliminación de todas las formas de trabajo forzoso u obligatorio, la abolición del trabajo infantil y de la discriminación en materia de empleo y ocupación.

Se señala la importancia de tomar medidas para que los trabajadores tengan conocimiento de las condiciones laborales que regirán la relación de trabajo, esto mediante un contrato por escrito, y también se prevé la igualdad de trato entre los trabajadores domésticos y los trabajadores en general en lo relativo a jornadas, salario y periodos de descanso, entre otros.

10 OIT, Ratificaciones por país del Convenio sobre las trabajadoras y los trabajadores domésticos, número 189, disponible en: http:// www.ilo.org/dyn/normlex/es/f?p=NORMLEXPUB :11300:0::NO::P11300_INSTRUMENT_ID:2551460 (fecha de consulta: 27 de julio de 2019).

11 OIT, Países que no han ratificado el Convenio sobre las trabajadoras y los trabajadores domésticos, número 189, disponible en: http://mmn.ilo.org/dyn/normlex/es/f? $p=$ NORMLEXP UB:11310:0::NO:11310:P11310_INSTRUMENT_ID:2551460:NO (fecha de consulta: 27 de julio de 2019). 
Como parte de las medidas que deben adoptar los Estados miembros, el Convenio señala: 1) El acceso de los trabajadores domésticos a tribunales y otros medios de solución de controversias en las mismas condiciones que cualquier otro trabajador, y 2) La práctica de medidas como la inspección del trabajo, aplicación de normas y sanciones de acuerdo a las características del trabajo doméstico.

Mientras que el Convenio 189 de la OIT es un instrumento jurídico vinculante (una vez ratificado), la Recomendación 201 tiene el carácter de orientadora para fortalecer y complementar las disposiciones del Convenio y así adaptarlas a las legislaciones de los Estados, por lo que deben analizarse de forma conjunta, pues contienen disposiciones específicas en beneficio de los trabajadores domésticos. Ambos instrumentos plantean un conjunto de derechos laborales y sociales que se equiparan al resto de los trabajadores.

Sobre este tema, la recomendación hace referencia a la necesidad de contar con servicios que orienten a los trabajadores domésticos para la comprensión de los términos en los que prestarán sus servicios y la implementación de los contratos de trabajo.

\section{CONCLUSIONES}

Es evidente la necesidad de una transformación en los sistemas jurídicos a fin de que reconozcan la importancia y valor que merece el trabajo doméstico, del hogar, de casas particulares, entre otras denominaciones que pudiera tener. Una legislación donde los derechos laborales se consagren con plena igualdad, pues la única condición especial que guardan los trabajadores del hogar respecto de los trabajadores ordinarios es su situación de vulnerabilidad y desprotección, bajo la creencia de que viven bien por la cercanía y convivencia con el patrón. Pero habría que detenerse a pensar si realmente esta cercanía implica una condición de bienestar y no de sujeción total al lugar de trabajo.

La intención de ubicar a los trabajadores del hogar en condiciones que propicien una igualdad en relación con el resto de los trabajadores no quiere decir que se dejen por un lado sus especificaciones al momento de actualizarse este tipo de relaciones de trabajo. El hecho de encontrar diversas concepciones y formas de regular esta labor es, precisamente, el resultado de los esfuerzos por integrar una ley o un apartado específico que atienda a las necesidades del servicio en sí y, evidentemente, no alejarlo de los estándares 
mínimos reconocidos para todo trabajador. Sin lugar a dudas, en la medida que surjan cambios a dicha conceptualización es como impactará en el reconocimiento de derechos para esta categoría de trabajadores.

Lo que reviste de "especial" a este sector de trabajadores, más que referirse a la ausencia de un lucro para el patrón, es la problemática que representa desenvolverse en un ambiente privado, como lo es el hogar de una familia, de ahí que para efectos de la fiscalización de las obligaciones de patrones, la Inspección del Trabajo y las figuras análogas a esta institución jurídica se vean impedidas de examinar y vigilar el cumplimiento de las normas de trabajo en determinados países.

Con el presente trabajo se identificaron los aspectos que comparten los países de Argentina, Chile, Ecuador, México y Uruguay sobre la regulación del trabajo del hogar y sus puntos de discrepancia, a fin de comparar la aproximación de esa igualdad entre los trabajadores considerados ordinarios y los que guardan características particulares, llamados "trabajos especiales".

De manera particular se señala que, en lo que respecta a México, está pendiente la ratificación del Convenio 189 y su Recomendación 201, relativa al reconocimiento de derechos de este grupo y el trabajo que los Estados deben de realizar para hacerlos efectivos y lograr el anhelado trabajo decente al que hace referencia la OIT. Además de la implementación de prácticas que promuevan la concientización de que el sector doméstico es tan importante como cualquier otro, o que incluso debe recibir mayor protección.

Como resultado de este estudio se puede concluir que México debe poner mayor atención a las adecuaciones que han realizado otros países de América Latina para hacer uniformes las condiciones de trabajo para todos los sectores. Asimismo, la situación de aquellos países tras la ratificación del Convenio 189 a fin de crear un panorama que los proteja, toda vez que comienza una nueva era para el trabajo del hogar a raíz de las reformas laborales sustantivas y procesales de este año 2019.

Hemos sido testigos de que aspectos como la brecha salarial, la conservación de regímenes especiales tanto laborales como de seguridad social, contextos culturales o la informalidad, entre otros, han sido obstáculos para regular esta actividad de forma adecuada y promover su reconocimiento y valor.

Sin lugar a dudas, los avances en materia de derechos laborales de este colectivo representan el resultado de largas luchas históricas, nada sencillas, por los factores mencionados. No obstante, poco a poco podemos encontrar leyes más benéficas y protectoras que llegan a ajustarse a esos parámetros 
internacionales fijados por la OIT. A pesar de los avances que se han presentado, la lucha contra la discriminación en este tipo de trabajo sigue vigente.

\section{FUENTES DE CONSULTA}

COMisión NACIONAL de los SAlarios Mínimos, disponible en: https:/ / wwm.gob. $m x$ / conasami/prensa/ hasta-diciembre-se-fijaran-los-salarios-minimos-gene rales-y-profesionales-donde-se-incluira-el-de-las-trabajadoras-del-bogar.

ORGANiZACiÓn INTERNACIONAL DEL TRABAjO, Países que no han ratificado el Convenio sobre las trabajadoras y los trabajadores domésticos, número 189, disponible en: http:// www.ilo.org/dyn/normlex/es/f?p=NORML EXPUB:11310:0::NO:11310:P11310_INSTRUMENT_ID:2551460:NO.

Organización InternaCiOnAL Del TRABAjO, "Panorama Laboral de América Latina y el Caribe 2017”, OIT, 2017, disponible en: https: / wmw. ilo.org/wcmsp5/groups/public/---americas/---ro-lima/documents/publication/ wcms_613957.pdf.

ORGANIZACIÓN INTERNACIONAL DEL TRABAJO, "Panorama temático laboral. Presente y futuro de la protección social en América Latina y el Caribe", OIT, 2018, disponible en: https://wmw.ilo.org/womsp5/groups/public/--americas/---ro-lima/documents/publication/woms_633654.pdf.

ORGANIZACIÓN INTERNACIONAL DEL TRABAJO, "Protección social del trabajo doméstico: tendencias y estadísticas", OIT, 2016, disponible en: https:// www.ilo.org/womsp5/groups/public/---ed_protect/---soc_sec/documents/pu blication/woms_458939.pdf.

Ratificación del Convenio 189, disponible en: https://www.ilo.org/dyn/norm lex $/$ es $/ f ? p=$ NORMLEXPUB:11300:0::NO::P11300_INSTRUMENT_ ID:2551460.

Ratificaciones por país del Convenio sobre las trabajadoras y los trabajadores domésticos, número 189, disponible en: http://wmw.ilo.org/dyn/norm lex/es/f?p=NORMLEXPUB:11300:0::NO::P11300_INSTRUMENT_ ID:2551460.

Unión Personal Auxiliar de Casas Particulares, Resolución de la Comisión Nacional de Trabajo en Casas Particulares en Argentina, disponible en: https:// www.upacp.org.ar/?page_id=1329. 